\title{
Raising the portcullis: some notes after having cataracts removed from my eyes
}

Cataract from Greek kataraktes, meaning waterfall or portcullis, an obstruction that descends from above. Portcullis in front of the left eye removed. On the right eye the cataract remains.

I play, looking at an object and then closing first my left eye, then the right. The two visions are distinctly different. Define the difference(s).

With the right eye alone, everything looks worn, with the left eye alone, everything looks new. This is not to say the object being looked at changes its evident age; its own signs of relative age or freshness remain the same. What changes is the light falling on the object and being reflected off it. It is the light that renews or - when diminished - makes old.

Light which makes life and the visible possible. Perhaps here we touch the metaphysics of light (to travel at the speed of light means leaving behind the temporal dimension.) On whatever it falls, light bestows a quality of firstness, rendering it pristine although in reality it may be a mountain or a sea that is X million years old. Light exists as a continuous everlasting beginning. Darkness, by contrast, is not, as often assumed, a finality but a prelude. This is what my left eye, which can barely distinguish contours yet, tells me.

The colour which has come back to a degree that I did not foresee is blue. (Blue and violet with their short waves are deflected by the opacity of the cataract.) Not only the pure blues, also the blues which contribute to other colours. The blues in certain greens, in certain purples and magentas and in certain greys. It's as if the sky remembers its rendezvous with the other colours of the earth.

All these blues playing with the light create the shine of silver or tin. A shine that has nothing to do with the sedate glow of gold or copper. Silver is fast - see mercury. The silver shine of fish, running water, sunlight on leaves.

For my left eye the nights are now darker because of the sharper contrast with the shine of the days. Blue is also the colour of depth and distance.

Another difference between the vision of the two eyes concerns distance. The portcullis closes in. With my left eye I can step outside, and distance increases in two ways. I see further and, simultaneously, any measure of distance elongates itself: a kilometre becomes longer as does a centimetre. I become more aware of the air, the space, between things, because that space is full of light like a tumbler can be full of water. With cataracts, wherever you are, you are, in a certain sense, indoors!

As a result of my increased perception of space, my sense of the lateral - of what is happening from left to right, of what is parallel to the horizon - is increased. I am more aware of what is passing before me, as distinct from what is addressed to me. Just as distance becomes longer, largeness becomes larger.

Each pair of eyes inevitably has to carry its own horizon. But this extended sense of largeness and of the lateral encourages you to imagine (as happens in childhood) a multitude of alternative horizons. The portcullis came down from above. The horizons extend in every direction.

Behind my right eye hangs a burlap cloth; behind my left eye there's a mirror. I don't of course see either burlap or mirror. What I'm looking at, however, dramatically reflects their difference. Before the burlap the visible remains indifferent; before the mirror it begins to play.

May 30th. Unusually blue sky, by any standards, over Paris. I look up at a fir tree and I have the impression that the little fractal fragments of sky, which I see between the masses of pine needles, are the tree's blue flowers, the colour of delphiniums.

The quicksilver of the light now becomes opalescent and pearl-like. This in no way diminishes, however, the quality of firstness which the light bestows. As though light and what is lit arrive at the selfsame instant. (Is this not the secret of visibility?)

Tomorrow it will be 3 weeks after the operation. If I try to sum up the transformed experience of looking, I'd say it's like suddenly finding oneself in a scene painted by Vermeer. For example: The Kitchen Maid (Rijksmuseum, Amsterdam). You are looking at the objects and the bread on the table where there is the bowl, into which the maid is pouring milk from a jug, and the surface of everything you are looking at is covered with a dew of light, early morning drops of light. $* * * *$

More notes after the operation on my right eye (26 March 2010), whose cataract was more rigid and opaque.

This time the onrush of light is less specific and more generalised. It's not so much that things appear better lit, but, rather that I'm acutely aware of how everything is surrounded by light. The element of air has become the element of light. Just as fish live and swim in water: we live and move through light.

The newly found, ubiquitous light seems quiet and silent; it is shadows and darkness that are noisy.

The light places a hand on your back. You don't turn round because from a long, long time ago, you recognise its touch. It's what you first saw and never gave a name to.

The removal of cataracts is comparable with the removal of a particular form of forgetfulness. Your eyes begin to reremember first times. And it is in this sense that what they experience after the intervention resembles a kind of visual renaissance.

The white paper on which I'm writing today (2 days after the operation) is whiter than anything l've become used to seeing. I return to my mother's kitchen in my childhood: there were comparable whites on the table, in the sink, on the shelves. And those whites of paper and porcelain and enamel contained a promise which this white paper today recalls.

Let's be clear about the implications of what I'm saying. Clearly, during many decades after my childhood, I saw sheets of white paper as white as this one. But gradually the whiteness dimmed without my 
taking account of it. Consequently, what I called white paper, changed, grew dimmer. And this afternoon what's happening is not that I realise this with my intelligence, but that the whiteness of the paper rushes towards my eyes, and my eyes embrace the whiteness like a long-lost friend.

I'm writing on the paper with black ink. And blacks (as distinct from dark greys, dark blues or greens or browns) have acquired more weight, are heavier. Other colours flare or recede or penetrate but blacks look as though they have been deposited. Laid on top of. And this connects with their weight. The black of a natural substance - such as ebony or obsidian or chromite - is never pure black; other colours hide within it. The laid-on blacks are all man-made.

Before the operation, I made a coloured drawing of a flower - a blue pansy. I did so with the idea of making another drawing of the same flower after the operation

Neither drawing is a copy. Both of course are interpretations of what I saw. They didn't come direct from the retinas of my eyes. Yet the difference between them is, I reckon, similar to the difference between what I perceived before and after the removal of the cataract.

When I compare them now it is as if in the first drawing I was faithfully noting down a sequence of musical notes without being able to hear the vibrations of their physical sounds. In the second drawing the vibrations of those notes were there before my eyes.

The structure and form of the flower is unchanged, as is the botanical logic of its colouring. What has changed is the intimacy of its colouring. Its colours have become naked before my eyes.

After this operation, unlike the first, the treated eye began, an hour or two after the intervention, to hurt and this continued for about a day. With mild painkillers it was quite tolerable. The passage through this small pain was inseparable from my journey towards a newly visible world. I emerged from the pain at the threshold of a new visibility.

A surgical intervention to remove cataracts gives back to the eyes much of their lost talent. Talent, however, invariably implies a certain amount of effort and endurance as well as grace and benefit. And so the new visibility represented for me not only a gift but an achievement. Principally the achievement of the doctors and nurses who carried out the intervention, and also, to some small degree, the achievement of my own body.

The pain made me aware of this.

When you open a dictionary and consult it, you refind, or discover for the first time, the precision of a word. Not only the precision of what it denotes, but also the word's precise place in the diversity of the language.

With both cataracts removed, what I see with my eyes is now like a dictionary which I can consult about the precision of things. The thing in itself, and also its place among other things.

I'm far more aware of comparative scale: the small becomes smaller, the large larger, the immense more immense. And the same is true, not only of things, but of spaces. The small becomes more intimate, the large more extensive. And this is because details - the exact grey of the sky in a certain direction, the way a knuckle creases when a hand is relaxed, the slope of a green field on the far side of a house, such details reassume a forgotten significance.

The unstartling heterogeneousness of the existent has marvellously returned. And the two eyes, portcullises removed, again and again register surprise.

\section{John Berger}

\section{Acknowledgements}

Dedicated with gratitude to Professor Baudouin, Dr Dupont-Monod, and their team at the hospital at Quinze-Vingts, Paris.

DOI: 10.3399/bjgp10X509766

\section{COMMENTARY}

Writer and artist, John Berger, is a global treasure. In 1972, he won the Booker Prize for his novel $G$ and in December 2009 he was awarded the Golden Pen Award for a Lifetime's Distinguished Service to Literature. Back in 1967, in collaboration with the photographer, Jean Mohr, he produced what is considered by many to be the best book ever written about general practice. A Fortunate Man is an account of the life and work of a single-handed GP in a deprived rural area in the Forest of Dean. What is absolutely remarkable about the book is that it demonstrates an understanding of the transactions of general practice care which holds true to this day and yet it was written from outside general practice by a writer and a photographer who simply observed the work of a doctor over the course of a few weeks. It is an extraordinary achievement of empathic imagination. One of the legacies of this enduringly wonderful book is that John Berger has now offered this remarkable description of his recent experience of undergoing cataract surgery, to be distributed as widely as possible for patients facing the same procedure. We will be making it freely available on our website for downloading.

\section{Alec Logan}

DOI: 10.3399/bjgp10X502227 